\title{
Medium-term cryopreservation of rabies virus samples
}

\author{
Tereza D'ávila de Freitas Aguiar[1], Maria Fátima da Silva Teixeira[1], \\ Edmara Chaves Costa ${ }^{[2]}$, Allan Bezerra Vitaliano ${ }^{[1]}$, Carlos Henrique de Andrade Teles ${ }^{[1]}$, \\ Igor Ciríaco Barroso ${ }^{[1]}$, Ronaldo Pereira Dias ${ }^{[1]}$ and Nélio Batista de Moraes ${ }^{[1],[3]}$
}

[1]. Laboratório de Virologia, Universidade Estadual do Ceará, Fortaleza, CE. [2]. Universidade da Integração Internacional da Lusofonia Afro-Brasileira, Redenção, CE. [3]. Rede Nordeste de Biotecnologia, Universidade Estadual do Ceará, Fortaleza, CE.

\begin{abstract}
Introduction: The cryopreservation of rabies virus has been described in detail in the literature. To date, little information is available on the use of cryoprotective agents for cold preservation of this virus, and the available data focus only on short-term virus preservation. In this study, we investigated the medium-term cryopreservation of samples of rabies virus using different cryopreservation protocols. Methods: The cryopreservation protocols for the rabies virus samples were performed at $-20^{\circ} \mathrm{C}$ and were divided according to the variables of time and cryoprotectant type used. The laboratory tests (intracerebral inoculation of mice, viral titration and direct immunofluorescence) were performed at regular intervals (360 and 720 days) to assess the viability of the viral samples according to the different preservation techniques used. Results: After 1 year of cryopreservation, the fluorescence intensity of intracellular corpuscles of the rabies virus and the median survival time of the mice differed between the positive controls and the treatments with the cryoprotectants. After 2 years, most of the samples subjected to the cryopreservation protocols (including the controls) did not produce fluorescence. However, the virus samples exposed to the cryoprotectant sucrose (68\% solution) responded positively in the direct immunofluorescence assay and in the intracerebral inoculation of the mice. Conclusions: Medium-term cryopreservation of the rabies virus inactivates the viral sample. However, the cryoprotectant agent sucrose (68\%) produces a preservative effect in cryopreserved rabies virus samples.
\end{abstract}

Keywords: Cryopreservation. Rabies virus. Medium-term.

\section{INTRODUCTION}

Rabies typically presents as an acute, progressive and incurable viral encephalitis, and the reemergence of the disease has been responsible for thousands of deaths in humans. With its wide distribution, its impact on public health and its broad economic implications, rabies can be considered the most important viral zoonosis known ${ }^{1,2}$.

The focus of rabies virus research by biologists, agricultural and biomedical scientists and the pharmaceutical industry has been based primarily on the acquisition and maintenance of biological samples. Currently, recognition of the importance of microorganisms in human development has led to improved techniques for the conservation of diverse microbiological specimens $^{3,4}$. However, few studies have investigated the preservation of rabies virus samples.

Because cooling significantly delays the deterioration of perishable goods, the use of low temperatures favors the storage

\footnotetext{
Address to: Dra Tereza D'ávila de Freitas Aguiar. LABOVIR. Av. Paranjana 1700, Campus do Itaperi, 60714-903 Fortaleza, CE, Brasil.

Phone: 5585 3101-9849; Fax: 5585 3101-9849

e-mail: labovirfavetuece@yahoo.com.br

Received 4 July 2013

Accepted 19 November 2013
}

of living organisms in a state of suspended animation for long periods. Therefore, cryopreservation is one of the most widely used techniques for the conservation of microbial biodiversity ${ }^{4,5}$.

Cryopreservation involves the storage of material at low (between $-20^{\circ} \mathrm{C}$ and $-80^{\circ} \mathrm{C}$ in freezers) and ultra-low temperatures $\left(-150^{\circ} \mathrm{C}\right.$ in liquid nitrogen), allowing the preservation of a variety of cellular types or organisms ${ }^{4,6}$. Cryopreservation methods can be divided according to the maximum preservation time as follows: mediumterm (at $-20^{\circ} \mathrm{C}$ ) and long-term (at $-80^{\circ} \mathrm{C}$ or in liquid nitrogen) $)^{7}$.

However, the cryopreservation process can also have deleterious effects on biological materials, especially cell membranes, resulting in a phenomenon termed cryoinjury 8,9 . Cryoinjury is a lethal event linked to the formation of intracellular ice, water-flow out of the cell (dehydration) and increased intracellular concentrations of solutes ${ }^{8}$.

The primary purpose of protective substances, known as cryoprotective agents, is to prevent crystallization through decreased water activity. Cryoprotective agents are frequently included in cryopreservation systems to reduce or even prevent the damage that results from freezing biological materials?. These cryoprotective additives provide extracellular protection (non-penetrating agents, such as polyethylene glycol and sucrose) or intracellular protection (penetrating agents, such as dimethyl sulfoxide and glycerol $)^{10}$.

Biological differences create different responses to freezing systems and different cryoprotectants; therefore, there is a need to adjust or even restructure the preservation criteria according to the material under investigation ${ }^{5}$. 
There are numerous procedures for maintaining viral stocks that depend largely on the particular properties of each individual virus. In a study by Costa and colleagues ${ }^{11}$, different cryopreservation protocols were investigated for rabies virus samples stored for short periods at $-20^{\circ} \mathrm{C}$. The study demonstrated that after freezing for 30 days, the fluorescence intensity of the cryopreserved rabies virus particles was lower than that of the fresh samples. However, the use of sucrose as a cryoprotectant had a preservative effect in the short-term. There is no single, optimal or universal formula to assess the efficiency of medium- and long-term storage and preservation of the rabies virus. Therefore, in this study, the medium-term cryopreservation of rabies virus samples using different cryopreservation protocols was investigated.

\section{METHODS}

\section{Experimental animals}

Swiss albino mice (Mus musculus), aged 3 to 4 weeks and weaned, were obtained from a conventional colony maintained at the Central Vivarium (Bioterio Central, BIOCEN) at the Ceará Federal University (Universidade Federal do Ceará, UFC) in Brazil.

\section{Viral samples}

The fixed rabies strain, Challenge Virus Standard (CVS 31.2), was used in the experiments, and it was maintained through passaging in mouse brains and stored in a lyophilized state.

\section{Cryoprotective agents}

Four cryoprotective agents that are most commonly used in freezing protocols for microorganisms were investigated. In the literature, the concentrations of the cryoprotective agents vary: dimethyl sulfoxide (DMSO) is used from $1 \%$ to $32 \%$, glycerol (GLY) is used from $2 \%$ to $55 \%$, polyethylene glycol (PEG) 6,000 is used from $5 \%$ to $45 \%$, and sucrose (SUC) is used from $1 \%$ to $68 \%{ }^{8}$. The median and maximum concentrations of cryoprotective agents used in this study, respectively, were as follows: $10 \%$ and $32 \%$ DMSO, $10 \%$ and $55 \%$ GLY, $10 \%$ and $45 \%$ PEG and $10 \%$ and $68 \%$ SUC.

The cryoprotectants were diluted in phosphate-buffered saline (PBS, pH 7.2) (Laborclin ${ }^{\circledR}$, Campo Novo do Parecis, State of Mato Grosso, Brazil) and sterilized by filtration through a syringe filter containing a $0.22-\mu \mathrm{m}$ pore size polyethersulfone membrane (Millipore ${ }^{\circledR}$, Fisher Scientific, USA).

\section{Cryopreservation protocols}

The following procedure, developed by Costa and colleagues ${ }^{11}$, was used.

An intracerebral (IC) inoculation of Swiss albino mice (aged 3 to 4 weeks) was performed using $0.03 \mathrm{~mL}$ of the viral strain CVS 31.2 (10\% suspension). The animals exhibiting symptoms typical of rabies were euthanized in an agonal state, starting on the fifth day post-inoculation. The central nervous system (CNS) samples were collected immediately after euthanasia, and the brain tissue samples and $10 \%$ suspensions of the brain tissue samples were used in the experiments.

In total, 350 brains from mice infected with CVS 31.2 were used. To minimize the variability of the individual samples, the brain material was collected, combined and homogenized to form a composite (pooled) sample.

The pooled brain sample infected with the rabies virus was divided into $0.5 \mathrm{-g}$ aliquots. The experimental protocol consisted of 8 samples, representing 2 concentrations for each of the 4 cryoprotectants, as well as the positive and negative controls. For the positive controls, 1 sample was not exposed to any cryoprotectants (pure positive control-Challenge Virus Standard, PC-CVS), and a second sample was subjected to freezing in PBS at $\mathrm{pH} 7.2$ (positive control-phosphate buffered saline (PBS), PC-PBS). The negative control (NC) consisted of pooled brain tissue samples from mice IC inoculated with $0.03 \mathrm{~mL}$ of PBS ( $\mathrm{pH} 7.2$ ).

The cryopreservation protocols were performed at $-20^{\circ} \mathrm{C}$ and were divided according to time and the different cryoprotectants used. The laboratory tests (viral titration, direct immunofluorescence and biological tests) were performed at regular intervals (360 and 720 days) to assess the performance of the rabies virus samples preserved using the different techniques, as described by Costa and colleagues ${ }^{11}$.

\section{Freezing and thawing process}

The aliquots containing the brain samples infected with the rabies virus were equilibrated in $10 \%$ and $32 \%$ DMSO, $10 \%$ and $55 \%$ GLY, $10 \%$ and $45 \%$ PEG, $10 \%$ and $68 \%$ SUC or PBS for $20 \mathrm{~min}$ at $20^{\circ} \mathrm{C}$. After the equilibration period, the samples were transferred to $\mathrm{a}-20^{\circ} \mathrm{C}$ freezer and maintained in accordance with the experimental schedule.

The thawing process entailed exposing the samples to room temperature for 1 minute, followed by incubation in a water bath at $37^{\circ} \mathrm{C}$ until thawed. Immediately after thawing, the samples were removed from the water bath and maintained at $4^{\circ} \mathrm{C}$ for a short period until use.

The cryoprotectant must be removed immediately after thawing. Therefore, the aliquots stored in the cryoprotective agents were subjected to 2 consecutive washes, averaging 5 minutes per wash, in PBS ( $\mathrm{pH} 7.2$ ) at room temperature as follows: the suspensions containing the viral samples were diluted in $2 \mathrm{~mL}$ of PBS, equilibrated for $5 \mathrm{~min}$ at room temperature and centrifuged at $150-200 \mathrm{G}$ for $5 \mathrm{~min}$; then, the supernatants were discarded. The process was repeated a second time, and the pellet was resuspended in viral diluent and transferred to a sterile microcentrifuge tube for the viability tests.

\section{Viral titration}

The viral titration was based on 10-fold serial dilutions in viral diluent (PBS) using a 10\% (w/v) initial suspension of the mouse brain sample as the starting point ${ }^{12}$. Each viral dilution, with a volume of $0.03 \mathrm{~mL}$, was IC inoculated into litters consisting of 6 weaned mice (aged 3 weeks). The dilutions ranged from $10^{-1}$ to $10^{-6}$. This viral titration was also performed with the control PC-CVS samples. 
The inoculated mice were monitored for symptoms of rabies daily for 21 days, and the mortality rate was assessed. Starting on the fifth day post-inoculation, dead animals exhibiting pathognomonic neurological signs of the disease were considered positive for rabies. At the end of the observation period, the viral titers were calculated in accordance with the method described by Reed and Müench ${ }^{13}$ and the method developed by Kuehne ${ }^{14}$. The titers were expressed as $\log \mathrm{DL}_{50} / 0.03 \mathrm{~mL} / \mathrm{IC}(50 \%$ lethal dose using $0.03 \mathrm{~mL}$ via IC administration in mice).

\section{Direct immunofluorescence assay}

For the direct immunofluorescence (DIF) assay, the slides were prepared in accordance with the guidelines recommended by Dean and colleagues ${ }^{15}$, and modifications to the incubation period for the conjugate (as proposed by Roehe and colleagues ${ }^{16}$ ) were used to obtain improved fluorescence.

Smears of the infected brain cross-sections were prepared by pressing the cross-sections onto slides suitable for immunofluorescence and fixing the samples in acetone for $30 \mathrm{~min}$ in a freezer at $-20^{\circ} \mathrm{C}$. The slides were dried at room temperature and then stored at $-20^{\circ} \mathrm{C}$ until use.

For the direct immunofluorescence assay, the slides were placed at room temperature for $5 \mathrm{~min}$ and then incubated with $30 \mu \mathrm{L}$ of fluorescein isothiocyanate-conjugated anti-rabies antibody for 2 hours at $37^{\circ} \mathrm{C}$ in a wet chamber. Next, the slides were washed in PBS (pH 8.5) and rinsed in distilled water. The slides were then mounted in $90 \%$ glycerol in PBS (pH 8.5), covered with a cover slip and used for the readout.

The readout was performed using a Zeiss immunofluorescence binocular microscope equipped with an HBO (Mercury Vapour Short-Arc) 50 mercury vapor lamp, a VGI (Interferential Filter Green) exciter filter and a Zeiss 43 barrier filter at 400X magnification in dark-field. The fluorescence intensity observed in the smear was evaluated based on a subjective scale of intensity ranging from 0 to 4 , in accordance with the method described by Bingham and Merwe ${ }^{17}$. The following classifications were used to rate the fluorescence: $(-)$, absence of antigens on the smear; $(+)$, very few antigens, 1 or more particles in less than $50 \%$ of the microscopic fields of view; $(++)$, few antigens, 1 or more particles in less than $100 \%$ but more than $50 \%$ of the microscopic fields of view; (+++), abundant antigens, 1 or more particles in each microscopic field of view, with the number of particles per microscopic field being countable; and $(+++)$, very abundant antigens in all fields of view, with the number of particles per field of view being uncountable.

Each smear was examined independently by 2 individuals and classified using a double-blind system. If the examiners disagreed on the classification, the respective cases were reexamined to reach a consensus.

\section{Intracerebral inoculation test in mice}

The test suspension in a volume of $0.03 \mathrm{~mL}(30 \mu \mathrm{l})$ was IC inoculated using insulin syringes (Becton Dickinson (BD) ultrafine IITM, short needle, 31 gauge, $8 \mathrm{~mm}$ [5/16"] for 30 units or less). Groups of 6 weaned Swiss albino mice (aged between 3 and 4 weeks) were used per sample for the mouse IC inoculation test and the biological tests.
The mice were monitored daily for up to 21 days after the inoculation. The negative controls were inoculated with PBS (pH 7.2). The inoculated mice were maintained in cages in the quarantine area of the Virology Laboratory at the State of Ceará University (Laboratório de Virologia da Universidade Estadual do Ceará, Brazil) during the entire observation period. The animals were maintained at an average temperature of $20^{\circ} \mathrm{C}$ under a 12-hour light-dark cycle and were supplied with water and feed ad libitum.

Clinical signs were identified and reported using a system of numerical codes as follows: 1 , reduced water and food intake; 2 , apathy and goose bumps; 3 , incoordination; 4 , tremors and/or episodes of tetany; 5, paralysis; and 6, prostration (agonal state preceding animal death) (adapted from Koprowski ${ }^{12}$ ).

The biological test was performed on all samples of the mouse brain tissue subjected to the cryopreservation protocols (DMSO, GLY, SUC and PEG) and the positive and negative controls at the predetermined time intervals.

\section{Ethical considerations}

This Ethics Committee on Animal Use at the Ceará State University (Comissão de Ética para o Uso de Animais da Universidade Estadual do Ceará, CEUA/UECE, Brazil) approved this study (protocol number 08185881-7).

\section{RESULTS}

The viral titers were decreased in the PC-CVS sample subjected to the medium-term cryopreservation procedure at $-20^{\circ} \mathrm{C}$. After cryopreservation for 1 year (360 days; $\mathrm{T}_{360}$ ), the viral titer of the sample pool was reduced from 4.69 to 1.50 $\log _{10} 50 \% \mathrm{LD}_{50}$ compared with the sample preserved for 30 days $\left(\mathrm{T}_{30}\right)$. The sample preserved for 2 years (720 days; $\left.\mathrm{T}_{720}\right)$ demonstrated no titer.

The results of the viability tests for the rabies virus samples after medium-term cryopreservation (up to 2 years, $\mathrm{T}_{360}$ and $\mathrm{T}_{720}$ ), based on the use of internal and external cryoprotective agents, are shown in Table 1. At $\mathrm{T}_{360}$, significant differences were observed in the fluorescence intensity of the rabies virus intracellular corpuscles among the PC-CVS, PBS-PC and cryoprotectant treatments. The sample exposed to $68 \%$ SUC demonstrated the maximum degree of fluorescence intensity $(++++)$ (Figure 1A), followed by the PC-CVS, 10\% GLY and $55 \%$ GLY samples (fluorescence intensities of +++ ) and the sample exposed to $10 \%$ SUC (fluorescence intensity of ++ ). The samples exposed to $10 \%$ DMSO and 32\% DMSO demonstrated a minimum degree of fluorescence intensity $(+)$. In contrast, the samples exposed to 10\% PEG and 45\% PEG did not demonstrate fluorescence and were designated negative for the presence of viable virus.

Table 1 also shows that according to the viability test, biological tests and direct immunofluorescence, the viability of the rabies virus was compromised after 2 years $\left(\mathrm{T}_{720}\right)$ of cryopreservation at $-20^{\circ} \mathrm{C}$. There was a significant decrease in fluorescence at $\mathrm{T}_{720}$ for all the cryopreservation protocols; the 
TABLE 1 - Effects of cryopreservation at $-20^{\circ} \mathrm{C}$ on rabies virus samples as evaluated by viral viability tests, the intracerebral inoculation of mice and direct immunofluorescence after exposure to internal and external cryoprotectants.

\begin{tabular}{|c|c|c|c|c|c|c|c|c|}
\hline \multirow[b]{3}{*}{ Samples } & \multicolumn{6}{|c|}{ Intracerebral inoculation test in mice } & \multirow{2}{*}{\multicolumn{2}{|c|}{ 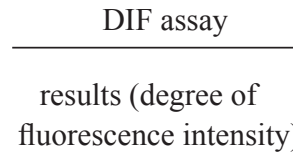 }} \\
\hline & \multicolumn{2}{|c|}{ MST (days) } & \multirow{2}{*}{$\begin{array}{c}\text { NMA/NMT } \\
\mathrm{T}_{360} \\
\end{array}$} & \multirow[b]{2}{*}{$\%$} & \multirow{2}{*}{$\frac{\mathrm{NMA} / \mathrm{NMT}}{\mathrm{T}_{720}}$} & \multirow[b]{2}{*}{$\%$} & & \\
\hline & $\mathrm{T}_{360}$ & $\mathrm{~T}_{720}$ & & & & & $\mathrm{~T}_{360}$ & $\mathrm{~T}_{720}$ \\
\hline $\mathrm{NC}$ & 21 & 21 & $0 / 6$ & 0.0 & $0 / 6$ & 0.0 & - & - \\
\hline PC-PBS & 8.7 & 21 & $6 / 6$ & 100.0 & $0 / 6$ & 0.0 & + & - \\
\hline DMSO $10 \%$ & 9.8 & 21 & $6 / 6$ & 100.0 & $0 / 6$ & 0.0 & + & - \\
\hline DMSO $32 \%$ & 7.3 & 21 & $6 / 6$ & 100.0 & $0 / 6$ & 0.0 & + & - \\
\hline GLY $10 \%$ & 7.4 & 21 & $6 / 6$ & 100.0 & $0 / 6$ & 0.0 & +++ & - \\
\hline SUC $10 \%$ & 6.8 & 21 & $6 / 6$ & 100.0 & $0 / 6$ & 0.0 & ++ & - \\
\hline SUC 68\% & 6.7 & 14.3 & $6 / 6$ & 100.0 & $6 / 6$ & 100.0 & ++++ & ++ \\
\hline
\end{tabular}

MST: mean survival time; NMA: number of mice affected; NMT: number of mice tested; DIF: direct immunofluorescence; degree of fluorescence intensity:,,,-++++++ and ++++ . NC: negative control; PC-CVS: positive control - Challenge Viral Standard; PC-PBS: positive control - phosphate buffered saline ; DMSO: dimethyl sulfoxide; GLY: glycerol; PEG: polyethylene glycol; SUC: sucrose.
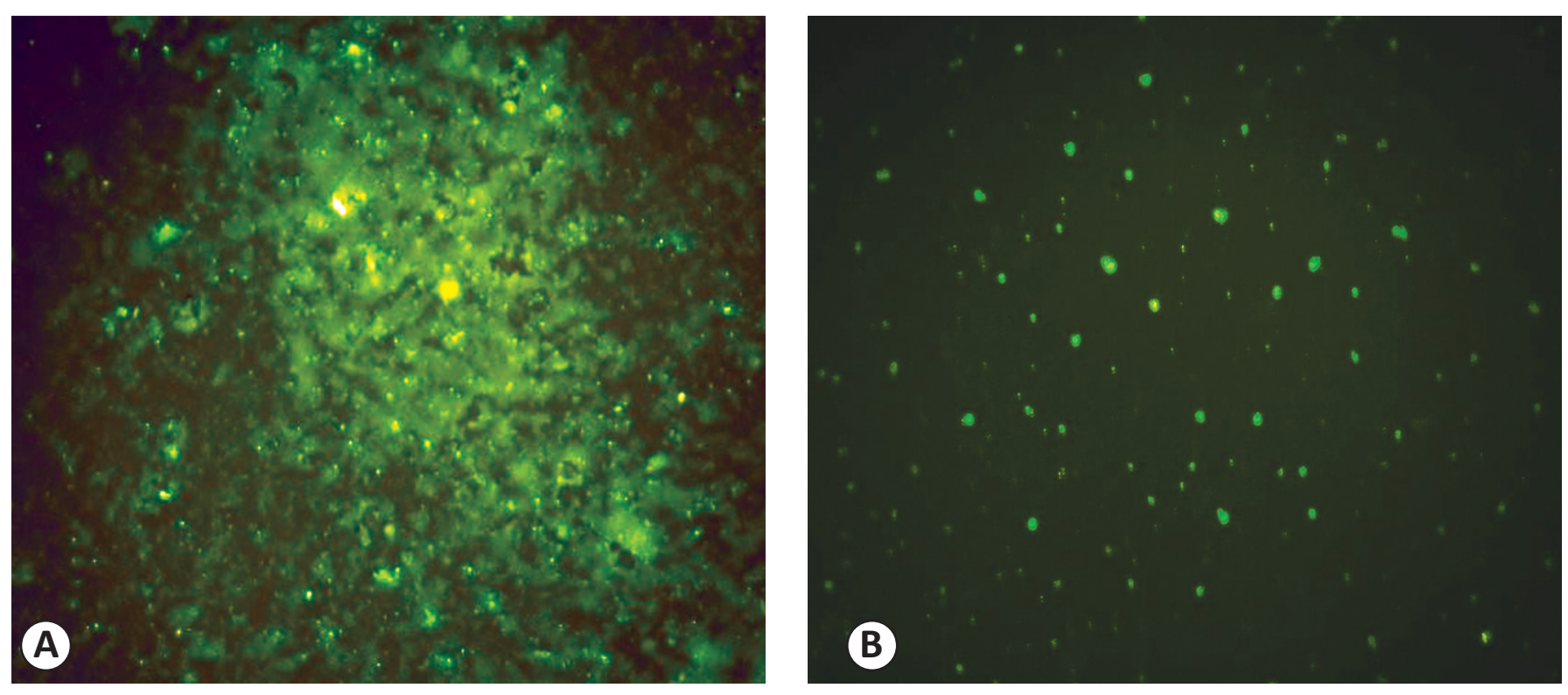

FIGURE 1 - Photomicrographs of direct immunofluorescence reactions in the presence (A and B) of rabies virus antigens in the brain tissue samples subjected to cryopreservation at $-20^{\circ} \mathrm{C}$ for up to 2 years (immunofluorescence microscope equipped with $400 \mathrm{X}$ magnification; Carl Zeiss, Germany). A: Cryopreservation in $68 \%$ SUC for 1 year demonstrating very abundant antigens in all fields of view, uncountable (++++). B: Cryopreservation in $68 \%$ SUC for 2 years demonstrating few antigens, 1 or more particles in less than $100 \%$ but more than $50 \%$ of the fields of view (++). SUC: sucrose Source: LABOVIR-UECE, 2012. 
majority of the samples were negative, including the positive controls. However, the sample exposed to $68 \%$ SUC continued to exhibit fluorescent intracellular corpuscles at a ++ degree of intensity (Figure 1B).

Throughout the experiment, the samples of normal mouse brain (NC) demonstrated negative results, as expected.

\section{DISCUSSION}

The viral titer measurements provided key data on viral viability before and after the cryopreservation of the rabies virus samples for up to 2 years. After 1 year of cold preservation, the titer of the pooled sample demonstrated a decrease compared with the sample preserved for 30 days, and the virus was undetectable after 2 years of cryopreservation. These data are consistent with those from a report by Costa and colleagues ${ }^{11}$, in which the viability of rabies virus samples was compromised after freezing/thawing in the absence of cryoprotective agents. Furthermore, according to Costa and colleagues ${ }^{11}$, periodic titration is a crucial step for the evaluation of cryopreserved viral samples.

Most rabies diagnostic laboratories frequently receive suspicious materials, and the materials are often maintained under inadequate preservation conditions. However, according to Kissling ${ }^{18}$, diagnosis is still possible. Indeed, Winkler and Adams ${ }^{19}$ reported that the direct immunofluorescence assay demonstrated the presence of rabies antigens even in decomposed materials. However, the data in our study failed to corroborate the findings of these previous reports. Indeed, the direct immunofluorescence assay demonstrated a significant decrease in the titer of the rabies virus samples preserved in the absence of cryoprotectant at $-20^{\circ} \mathrm{C}$ for 1 year, and the samples were negative after preservation for 2 years.

In this study, the viral viability of cryopreserved rabies virus samples (with or without cryoprotectant) was compromised significantly by freezing at $-20^{\circ} \mathrm{C}$ for up to 2 years, as assessed by the direct immunofluorescence assay and the IC inoculation of mice. These data are consistent with the findings of Costa and colleagues ${ }^{11}$, demonstrating that the fluorescence intensity of rabies virus particles in samples subjected to short-term cryopreservation ( 30 days) at $-20^{\circ} \mathrm{C}$ was lower than that of fresh samples. These observations likely reflect mechanical damage caused by the formation of ice crystals during freezing at this temperature. A study performed by Olson and colleagues ${ }^{20}$ demonstrated increased viral loss at $-20^{\circ} \mathrm{C}$, emphasizing that viral samples should not be stored at $-20^{\circ} \mathrm{C}$ because of ice crystal formation and the consequent possibility of damage to the viral structure.

Furthermore, according to Greene and Rupprecht ${ }^{21}$, the storage of rabies virus samples in domestic freezers at a minimum temperature of $-20^{\circ} \mathrm{C}$ with repeated freeze-thaw cycles causes damage to the tissues; this type of storage should be avoided because viral antigen degradation and loss of viability may affect the sensitivity of the diagnostic tests and preclude future viral detection. For the long-term maintenance of rabies virus samples used for epidemiology studies and other purposes, rabies-positive samples should be maintained at very low temperatures $\left(-30\right.$ to $\left.-80^{\circ} \mathrm{C}\right)$ to preserve the viral activity for several years (Mizuno and colleagues ${ }^{22}$; Biswal and colleagues ${ }^{23}$ ).

Regarding the intracerebral inoculation results, there was a significant increase in the mean survival time of inoculated mice (14.3 to 21 days) that correlated with the cryopreservation time at $-20^{\circ} \mathrm{C}$ in both the presence and absence of a cryoprotective agent. According to Lopes and colleagues ${ }^{24}$ and Costa and colleagues ${ }^{11}$, the increase in the mean animal survival time is due to a lower virulence of the viral sample caused by the storage period and/or preservation conditions, given that the mean survival time of mice inoculated with the rabies virus preserved in an appropriate manner varies from 7 to 10 days and the mean survival time for animals inoculated with the positive control (Challenge Virus Standard strain) ranges from 5 to 7 days.

In this study, sucrose at the maximum concentration of $68 \%$ exerted a significant protective effect on rabies virus particles that were cryopreserved at $-20^{\circ} \mathrm{C}$ for 1 or 2 years. The rabies virus samples preserved in the sucrose cryoprotectant at this concentration demonstrated a maximum degree of fluorescence intensity after 1 year of cold preservation, and they were the only samples that contained fluorescent rabies virus antigens after 2 years of cryopreservation. These data are consistent with the findings of Costa et al. ${ }^{11}$, in which the efficacy of sucrose for the short-term cryopreservation of rabies virus was demonstrated. According to Crowe and colleagues ${ }^{25}$ and Woelders and colleagues $^{26}$, a number of sugars, including sucrose, prevent the damage caused by the cellular dehydration that occurs during the freezing process by stabilizing the lipid bilayer and promoting changes in the plasma membrane permeability and the lateral separation of components.

Furthermore, Chen and colleagues ${ }^{27}$ suggested that the increase in sucrose concentration generates an osmotic gradient throughout the cellular membrane that draws water out of cells and causes the cells to become sufficiently dehydrated before and during the freezing process, which has a protective effect on the viral particles.

In conclusions, medium-term cryopreservation of the rabies virus inactivates the viral samples; the viral sample titers were negative after 2 years of preservation. However, the cryoprotective agent sucrose, at a concentration of $68 \%$, produces a preservative effect on the rabies virus, allowing the detection of intracellular fluorescent corpuscles, even after 2 years of cryopreservation.

\section{ACKNOWLEDGMENTS}

We are grateful to Ceará State University (Universidade Estadual do Ceará) for the institutional support and to Dr. Phyllis Catharina Romijn, researcher at the Agricultural Research Company of the State of Rio de Janeiro (Empresa de Pesquisa Agropecuária do Estado do Rio de Janeiro, PESAGRORIO), for kindly providing the viral sample used in the study. 


\section{CONFLICT OF INTEREST}

The authors declare that there is no conflict of interest.

\section{FINANCIAL SUPPORT}

Fundação Cearense de Apoio ao Desenvolvimento Cientifico e Tecnológico (FUNCAP) and Conselho Nacional de Desenvolvimento Científico e Tecnológico (CNPq).

\section{REFERENCES}

1. Hemachudha T, Laothamatas J, Rupprecht CE. Human rabies: a disease of complex neuropathogenetic mechanisms and diagnostic challenges. Lancet Infect Dis 2002; 1:101-109.

2. Rupprecht CE, Hanlon CA, Hemachudha T. Rabies re-examined. Lancet Infect Dis 2002; 2:327-343.

3. Holland NT, Smith MT, Eskenazi B, Bastaki M. Biological sample collection and processing for molecular epidemiological studies. Mutat Res 2003; 543:217-234.

4. Paoli P. Biobanking in microbiology: from sample collection to epidemiology, diagnosis and research. FEMS Microbiol Rev 2005; 29:897-910.

5. Day JG, Mclellan MR. Cryopreservation and freeze-drying protocols. New Jersey: Humana Press; 1995.

6. Wolfe J, Bryant G. Freezing, drying and/or vitrification of membranesolute-water systems. Cryobiol 1999; 39:103-129.

7. Sette LD. Técnicas de preservação de microrganismos [Methods of preservation of microorganisms; Internet]. Coleção Brasileira de Microrganismos de Ambiente e Indústria - CBMAI, CPQBA - UNICAMP; February 2005 [Cited 2011 September 27]. Available at: http://www.cria. org.br/eventos/confmt/presentations/Preservacao.ppt.

8. Hubálek Z. Protectants used in the cryopreservation of microorganisms. Cryobiol 2003; 46:205-229.

9. Costa EC. Conservação de amostras do vírus da Raiva mediante diferentes protocolos de criopreservação (Conservation of rabies virus samples using different protocols of cryopreservation). [Doctorate Thesis] [Fortaleza] Universidade Estadual do Ceará; 2010. 115p.

10. Meryman HT. Cryoprotective agents. Cryobiol 1971; 8:173-183.

11. Costa EC, Teixeira MFS, Aguiar TDF, Rolim BN, Romijm PC, Rocha MFG. Rabies virus viability after short-term cryopreservation using cryoprotectant agents. Rev Inst Adolfo Lutz 2011; 70:106-112.
12. Koprowski H. The mouse inoculation test. In: Meslin FX, Kaplan MM, Koprowski H, editors. Laboratory Techniques in Rabies. $4^{\text {th }}$ ed. Geneva: World Health Organization; 1996. p. 80-86.

13. Reed LJ, Müench H. A simple method of estimating fifty percent endpoints. Am J Hyg 1938; 27:493-497.

14. Kuehne RW. Rapid determination of $\log 1050 \%$ Lethal Doses or $50 \%$ Infective Doses. J Clin Microbiol 1983; 17:702-703.

15. Dean DJ, Abelseth MK, Atanasiu P. The fluorescent antibody test. In: Meslin FX, Kaplan MM, Koprowski H, editors. Laboratory Techniques in Rabies. $4^{\text {th }}$. Geneva: World Health Organization; 1996. p. 88-95.

16. Roehe PM, Schaefer R, Pereira AS. Otimização da imunofluorescência direta para diagnóstico de Raiva. Acta Sci Vet 2002; 30:53-57.

17. Bingham J, Merwe M. Distribution of Rabies antigen in infected brain material: determining the reliability of different regions of the brain for the Rabies fluorescent antibody text. J Virol Methods 2002; 101: $85-94$.

18. Kissling RE. The fluorescent antibody test in rabies. In: Baer GM. The natural history of rabies. New York: Academic Press; 1975. p. 401-416.

19. Winkler WG, Adams DB. Apud Kissling RE. The fluorescent antibody test in rabies. In: Baer GM. The natural history of rabies. New York: Academic Press; 1975. p. 401-416.

20. Olson MR, Axler RP, Hicks RE. Effects of freezing and storage temperature on MS2 viability. J Virol Methods 2004; 122:147-152.

21. Greene C, Rupprecht C. Rabies and other Lyssavirus infections. In: Greene C, editor. Infectious Diseases of the Dog and Cat. St Louis; 2006. p. 167-183.

22. Mizuno N, Nagamura H, Iwamoto K. RNA from decades-old archival tissue blocks for retrospective studies. Diagn Mol Pathol 1998; 7: 202-208.

23. Biswal M, Ratho R, Mishra B. Usefulness of reverse transcriptasepolymerase chain reaction for detection of rabies RNA in archival samples. J Infect Dis 2007; 60:298-299.

24. Lopes MC, Venditti LLR, Queiroz LH. Comparison between RTPCR and the mouse inoculation test for detection of rabies virus in samples kept for long periods under different conditions. J Virol Methods 2010; 164: 19-23.

25. Crowe JH, Crowe LM, Carpenter JF. Stabilization using dry phospholipid bilayers and proteins by sugars. Biochem J 1987; 242:1-10.

26. Woelders H, Mathiijs A, Engel B. Effects of trehalose, and sucrose, osmolality of the freezing medium, and cooling rate on viability and intactness of bull sperm after freezing and thawing. Cryobiol 1997; 35:93-195.

27. Chen ZJ, Li M, Li Y, Zhao LX, Tang R, Sheng Y, et al. Effects of sucrose concentration on the developmental potential of human frozenthawed oocytes at different stages of maturity. Hum Reprod 2004; 10:2345-2349. 